\title{
A RAZÃO DA INFLUÊNCIA: UMA TEORIA DO CLIMA ${ }^{1}$
}

\author{
João Afonso Zavattini
}

\begin{abstract}
RESUMO
Esta explanação, apresentada no VI SBCG, discute a influência exercida pelo Prof. Dr. Carlos Augusto de Figueiredo Monteiro na Climatologia Geográfica Brasileira, destaca a importância do conceito de clima (Sorre, 1951) e do paradigma do ritmo climático (Monteiro, 1971), e propõe um outro tipo de análise dos trabalhos dos discípulos do Mestre Monteiro, motivo pelo qual o livro "A Angústia da Influência: uma teoria da poesia" (Bloom, 2002) é usado como uma analogia.
\end{abstract}

Palavras chave: influência, Monteiro, ritmo climático, Brasil.

THE REASON OF INFLUENCE: A THEORY OF CLIMATE.

\begin{abstract}
This explanation, exhibited in the VI SBCG, discuss the PhD Carlos Augusto de Figueiredo Monteiro's influence on the Brazilian Geographical Climatology, accentuates the importance of climate's concept (Sorre, 1951) and the climatic rhythm's paradigm (Monteiro, 1971), and proposes a different type of analysis for the works of Master Monteiro's followers, thus the reason for the book "The Anxiety of Influence: a theory of poetry" (Bloom, 2002) being used as an analogy.
\end{abstract}

Keywords: influence, Monteiro, climatic rhythm, Brazil.

1 Palestra apresentada em mesa redonda do VI Simpósio Brasileiro de Climatologia, 13 a 16 de outubro de 2004, Aracaju, SE.

2 Departamento de Geografia - IGCE - UNESP de Rio Claro/SP. 


\section{PREÂMBULO: agradecimentos e advertência.}

Ao agradecer o lisonjeiro convite da prezada Profa Dra Josefa Eliane Santana de Siqueira Pinto, coordenadora do VI SBCG, formalizado na solicitação de contribuição para essa mesa-redonda em termos de "representante da Climatologia Geográfica, ao lado de um geógrafo, um meteorologista, um agrônomo e um biogeógrafo", gostaria - antes de tudo - de deixar bem claro que, de fato e de direito, representativo dessa área do saber no país é o Prof. Dr. Carlos Augusto de Figueiredo Monteiro. Sobre sua influência nos estudos brasileiros de clima muito eu já disse e, nesta oportunidade, uma vez mais o farei.

Queria, ainda, registrar a grata satisfação de constatar que dessa mesa, conforme programação recebida, também faria parte o Doutor Divino Moura, que mesmo sem saber representou, como no caso daquele professor, significativo papel em minhas pesquisas de mestrado e doutorado. Às bases teóricas e metodológicas (análise rítmica, anos-padrão, tipologia dos fluxos polares etc.) oferecidas pelo geógrafo Carlos Augusto de Figueiredo Monteiro (USP) somar-se-ia o material (dados de superfície e cartas isobáricas) disponibilizado pelo meteorologista Antônio Divino Moura (INPE, INMET). É um privilégio poder demonstrar, publicamente, o quão importantes eles foram para minha vida profissional.

Iniciando a contribuição propriamente dita, pediria a devida compreensão e paciência, pois precisarei recordar certas passagens de minha formação universitária e da modesta carreira até aqui desenvolvida, diretamente ligadas à influência exercida pelo semeador do ritmo do clima no Brasil. Gostaria de informar, também, que no texto a seguir comparecerão algumas idéias extraídas do livro "A angústia da influência: uma teoria da poesia", de Harold Bloom (Imago Editora, Rio de Janeiro, 2002), donde o título desta contribuição. Contudo, devo advertir, não se trata de paródia nem de paráfrase, mas apenas de um texto muito singelo, que contém opiniões - talvez de maneira diversa das anteriores - que venho sustentando há mais de um decênio e que tenho procurado - no escopo da Geografia - oferecer ao debate. Além do mais, o texto pode ser tomado como réplica ao prefácio do Professor Monteiro, em obra recente de minha autoria e inteira responsabilidade.

\section{PASSAGENS: coração (sensibilidade) versus razão (responsabili- dade).}

Em 1974, não tendo sido possível estudar arquitetura na capital sonho jamais realizado - fui parar em Presidente Prudente, cidade próxima da minha terra natal, onde cursaria Geografia na outrora Faculdade de Filosofia, Ciências e Letras, uma autarquia estadual, hoje UNESP. Nesse mesmo ano viria a conhecer - da platéia - o Professor Monteiro, então às voltas com uma tal de "black box", algo muito inusitado para a mente de um jovem caipira do oeste paulista, que nem ousou apresentar-se ao professor e que ficou, como se diz, matutando sobre a palestra e o palestrante. Há exatos trinta anos!

Além das aulas freqüentadas, como era monitor-bolsista do departamento, tinha por obrigação auxiliar nas "leituras" diárias da estação 
meteorológica padrão, contígua à faculdade. No segundo semestre de 1975 eu já era observador meteorológico concursado. Nesse mesmo ano, uma excursão didática à capital paulista conduzida por Armen Mamigonian - grande amigo do Professor Monteiro - nos permitiria conhecer o Departamento de Geografia da USP. Ainda hoje me lembro dos dois amigos a conversar, dentre outras coisas, sobre a tese de livre-docência em processo final de feitura, essa que todo mundo conhece (Monteiro, 1976), referencial teórico obrigatório daqueles que enveredam pela climatologia urbana. Mais uma vez preferi apenas observar, sem me aproximar do professor. Caipira é assim mesmo! Ou era? Passou mais um ano e lá se foi 1976.

Entretanto, em 1977, o Professor Sílvio Carlos Bray - que há dois anos estava em Presidente Prudente - não apenas me apresentaria ao Professor Monteiro como me presentearia com obras de sua biblioteca, hoje verdadeiras raridades da climatologia. Foi quando pude, finalmente, mostrar o trabalho que realizava no posto meteorológico da faculdade. Ali, o famoso professor aventou a possibilidade de me orientar na USP e indicou - através daqueles seus preciosos esboços - um estudo de clima para a cidade que, mais tarde, viria a ser feito por uma outra pessoa.

Em janeiro de 1978, recém-formado, fui estagiar no setor de previsão do tempo do 70 Distrito de Meteorologia do INMET, em São Paulo/SP, e aproveitei para procurar o Professor Monteiro, que me informou não possuir vaga disponível para aquele ano, no curso de pós-graduação. Foi quando ele me sugeriu tentar a seleção com o Professor Titarelli, seu colega de departamento, que se tornaria meu orientador tanto de mestrado como de doutorado. Desse modo, ao invés de me encaminhar para os estudos de climatologia urbana voltei-me para a dinâmica atmosférica regional, com ênfase na distribuição da pluviosidade e na classificação climática de base genética.

A partir do ano de 1981 daria início à minha carreira universitária. Em 1984, ainda um ingênuo professor do campus da UNESP de Presidente Prudente, pensava que a Revista de Geografia da UNESP, também em seus primeiros momentos de existência, certamente iria me prestigiar com a publicação do artigo "Ritmo Atmosférico e Variações Pluviais em Presidente Prudente (SP) - 1983", que submetera à sua apreciação. Qual não foi a minha surpresa - típica de novatos da academia - ao receber as manifestações dos seus dois revisores. Um deles havia sido lacônico, mas favorável à publicação do artigo, ao passo que o outro, não apenas tecia algumas considerações um tanto quanto desabonadoras, como, ainda, à margem do parágrafo ${ }^{3}$ no qual eu empregara o termo análise rítmica, fazia a seguinte indagação: "O que é análise rítmica?"

Indignado, tanto por causa de minha inexperiência em publicar como pela maneira daquele revisor manifestar-se, pus-me a refletir sobre os fatos. Pensava, então, à época: Por que essa revista universitária nascente não é capaz de apoiar a publicação de um artigo escrito por um membro de sua comunidade, recentemente "tornado" professor? Como se recusam a divulgar esse material, principalmente em se tratando de algo escrito à luz do paradigma preconizado pelo eminente geógrafo Carlos Augusto de Figueiredo Monteiro? Por que ignoram uma contribuição que aborda as chuvas

3 O parágrafo apenas dizia: "Inicialmente coletamos os dados necessários para elaborar o gráfico de Análise Rítmica (MONTEIRO, 1971). 
excepcionais ocorridas em 1983, ano em que a comunidade científica finalmente havia despertado para o ritmo do fenômeno El Niño e para as conseqüências dele advindas?

Tudo isso me era difícil de compreender. Afinal, julgava: o artigo é claro e transparente. Tanto quanto o são - ao menos eu acreditava - o conceito de ritmo climático e o paradigma da análise rítmica em Climatologia. Ledo engano ${ }^{4}$ ! Deveria era ter atentado para o "sinal" que estava sendo enviado. Afinal, a recusa daquele revisor (certamente um colega universitário) e, principalmente, sua indagação deveriam ter-me servido de alerta.

Ora, distante daquele momento inicial de minha carreira e já havendo percorrido tantos caminhos - o tempo a meu favor - posso mesmo crer que subestimei a revista e que superestimei a penetração do paradigma. Faltou-me perspicácia! Hoje, após a realização da tese de livre docência (Zavattini, 2001), um extenso levantamento da produção na área de climatologia - com inventário das teses e dissertações dos programas de pósgraduação em geografia da USP e UNESP, posso concluir que, não resta dúvida, o fato narrado era mesmo um "sinal".

Naturalmente, no caso do paradigma da análise rítmica, aquela frustração de início de carreira bem que poderia ter-me feito descartá-lo. Porém, longe disso, já o tendo utilizado na dissertação de mestrado (Zavatini, 1983), novamente o empregaria na tese de doutorado (Zavatini, 1990), quando ao estudar a dinâmica atmosférica e as chuvas no Mato Grosso do Sul recorri ao instrumental de informática então disponível.

Todavia, o que na verdade eu poderia ter feito - após aquela recusa de 1984 - era ter divulgado melhor esse paradigma, usando-o ainda mais, detalhando-o ainda mais, e insistindo em publicar resultados obtidos a partir do seu uso. Enfim, creio que deveria tê-lo aplicado, também, em outras pesquisas, sob minha orientação. Afinal, será que o fiz? Isto, porque, uma contribuição desse porte, preconizada pelo Professor Monteiro, mereceria ter sido mais empregada e, ouso dizer, deveria ser melhor compreendida, pois o espectro para suas aplicações é muito amplo, sejam no âmbito da Geografia ou de outros ramos do conhecimento $e$, assim, continuo a sustentar que as oportunidades não estão sendo bem aproveitadas.

Voltando, porém, à surpresa inicialmente relatada, para aquele "sinal" que me chegara muito fraco, nos idos de 1984 - possivelmente por causa da ingênua indignação do professor universitário principiante - gostaria, agora, de considerá-lo sob uma outra ótica. O que estou querendo dizer é que se não tivesse ficado irritado, como fiquei, e se não tivesse desistido de publicálo, como o fiz, se ao invés disso tudo, tivesse eu reformulado aquele artigo e o tivesse submetido novamente à apreciação, talvez agora estivesse vivendo um outro momento em minha vida acadêmica e, certamente, não estivesse participando dessa mesa-redonda com a presente contribuição. Ou seja, talvez hoje as coisas fossem diferentes. Ou talvez não. Quem é que sabe? O que importa, neste momento, é que de lá para cá, dois decênios já se passaram e, frustrações à parte, gostaria que o progresso na área da Climatologia Geográfica tivesse sido maior. Afinal, o conceito de ritmo - teoria do clima que

\footnotetext{
4 Até hoje guardo comigo o artigo, como uma prova dessa minha tentativa - primeira e frustrada de publicar por meio da nossa própria imprensa universitária. A tentativa, em 2002, de publicar a tese de livre-docência pela Editora da UNESP me mostraria novos ângulos dessa mesma questão.
} 
remonta a Sorre - apresenta clara divergência metodológica de aplicação por Pédelaborde, na França, e no Brasil, por Monteiro. E, novamente, lá vou eu demonstrá-la, mesmo correndo o risco de angustiar o Mestre, que não gosta que the atribuam o papel de criador da "escola brasileira de climatologia geográfica".

\section{O SEMEADOR, A ESCOLA E O PARADIGMA: outras proporções (re)visionárias?}

Já no resumo de "Clima e Excepcionalismo: conjecturas sobre o desempenho da atmosfera como fenômeno geográfico", o Mestre revela que a terceira parte "Fatos Coleantes e Relação Persistente (resultados e limitações num procurar)" é o core da obra, pois é quando "retorna às origens das propostas primeiras, rediscutindo a mudança de paradigma, a influência conceitual obtida em Max Sorre e suas estratégias pessoais de pesquisa, para atingir a nova postura necessária aos propósitos geográficos" (Monteiro, 1991, p.ii). Esse assunto, que venho abordando desde o primeiro simpósio de climatologia geográfica em 1992, mereceu do Professor Monteiro a seguinte explicação:

A aceitação do conceito de Max SORRE (1951) deu margem à adoção de um novo paradigma que não encontraria apoio em uma estratégia metodológica, de vez que SORRE não produziu análises climatológicas. A estratégia proposta por PÉDELABORDE (1957) foi descartada, de vez que ele se preocupava antes com o levantamento da "totalidade dos tipos de tempo", enquanto a mim interessava mais o mecanismo "seqüencial" desses tipos, dando atenção às suas peculiares irregularidades, posto que estas se constituem (longe de ser "exceções") em eventos de imensa importância aos processos de interação geográfica. [...] A estratégia de projeção temporal foi feita a base da escolha de "anos padrão" que representassem os diferentes graus de proximidade do ritmo "habitual" ao lado daqueles afetados por irregularidades na circulação a modo de promover acidentes e impactos nas atividades humanas. Os períodos de observação não se prendiam aos 30 anos exigidos para o cálculo de "normais". Optava-se por segmentos menores, usualmente dez anos, compensados por uma homogeneidade de períodos de observação para todas as localidades numa área teste ou universo de análise. [...] A técnica utilizada na assim proposta "análise rítmica" - segundo as condições e recursos disponíveis - consistia na montagem de um gráfico de representação simultânea dos elementos do clima em sua variação "diária", acoplando a representação gráfica da seqüência de alternância dos diferentes sistemas meteorológicos envolvidos na circulação secundária (Monteiro, 1991, p.38-39).

que:

Sobre o "geográfico" na climatologia o Mestre há muito já havia dito

Acreditamos que a abordagem alcança o nível geográfico quando colocamos a análise dos tipos de tempo em seqüência contínua. Embora nas mais diferentes escalas de tempo ou espaço - desde a análise comparativa de vários anos tomados como padrões representativos da circulação de um continente, nas variações sazonais dentro de um ou alguns anos numa região, até a análise episódica de um fenômeno local - será necessária a continuidade da seqüência. Por coerência com a noção de "sucessão" de que se reveste o caráter geográfico do clima. Porque só o encadeamento dos estados atmosféricos mostra os "tipos" esquematizados na análise 
meteorológica precedente, em suas perspectivas reais, revestidos de suas infinitas gradações e facetas. Também é pela sucessão que se percebem as diferentes combinações dos elementos climáticos entre si e suas relações com os demais elementos do quadro geográfico. É a seqüência que conduz ao ritmo, e o ritmo é a essência da análise dinâmica (Monteiro, 1969, p.13). Pédelaborde:

$E$, finalmente, eis como ele compara a sua abordagem com a de

Enquanto para Pédelaborde o paradigma (que certamente não é o estado médio da atmosfera, o que o aproxima de Sorre), seria "a totalidade dos tipos de tempo", para mim é o ritmo, ou seja, o encadeamento, sucessivo e contínuo, dos estados atmosféricos e suas articulações no sentido de retorno aos mesmos estados (Monteiro, 1976, p.30).

Creio que passa da hora do Professor Monteiro - o semeador do ritmo do clima no Brasil - aceitar, sem angústia, a insígnia de criador de uma escola, embora, a esse respeito, mais de uma vez ele já tenha se pronunciado (Monteiro, 1991, p.35-41; 2000, p.9-13). Todavia, a responsabilidade de sua influência, angústia à parte, deveria ser de todos nós. É preciso, sempre, ler e reler a Obra e reconhecer o Mestre, pois cada (re)leitura é um novo aprendizado. Propositadamente, não usei adjetivos qualificativos e sim maiúsculas, na esperança de que sua angústia seja branda e logo passe. Contudo, a sua contribuição à climatologia no Brasil, não tenho dúvida nem angústia, permanecerá. A esse respeito, um recente estudo confirma a influência do Mestre no âmbito da Geografia e mostra a boa colheita de três "safras" decenais inseridas no período de 1971 a 2000 (Zavattini, 2001; 2004).

E, a propósito do tema dessa mesa-redonda: "Climatologia Geográfica e interação com outros campos do conhecimento", alguns trechos daquela obra de 1991 (especialmente alguns da terceira parte) revelam como é frustrante para o Professor Monteiro, e creio que para todos da Climatologia Geográfica, a incompreensão dos meteorologistas no que respeita à nossa produção, melhor ainda, ao nosso referencial teórico. Já outros segmentos da citada obra demonstram, apesar de tudo, o bom humor do Mestre ao constatar que as contribuições pioneiras de Serra e Ratisbonna, por ele transpostas para a Geografia ${ }^{5}$, são ignoradas pela nova geração de meteorologistas, enquanto "novas verdades" vão sendo "reveladas". Seria, apenas e tão somente, pura prepotência "high-tech" de supercomputadores alimentados com dados inconsistentes?

Mas, interações com outros ramos do saber, além do meteorológico, a Climatologia Geográfica (vale dizer, o paradigma do ritmo) pode promover. Pode, porque nem sempre é usado como se deve. Tenho sempre a impressão de que alguns precisariam de "bula" para usá-lo corretamente. E, há casos, mesmo tendo o "usuário" lido a "bula", em que fica a impressão de que ele concentrou-se apenas na "posologia" ou, simplesmente, na "composição" da fórmula. Posso afirmar que fazer a crítica do emprego desse paradigma na

5 Revelando ter recorrido "à já valiosa contribuição dos meteorologistas brasileiros como fundamento à dinâmica da circulação" expõe que ao agir "sob ponto de vista geográfico, procuramos esquematizar ali os grandes tipos de estados atmosféricos ocorrentes na região, segundo os mecanismos da circulação em suas variações sazonais." Além disso, acrescenta: "Naquela tarefa de compilação procuramos fazer trabalho comparável àquele do músico que transpõe uma partitura destinada a um instrumento de sopro para um instrumento de corda. Tal diferença de natureza instrumental parece-nos, sem exagero, refletir as diferenças de alcance e propósitos entre Geografia e Meteorologia" (Monteiro, 1969, p.7). 
produção levantada ao longo de três décadas foi, por um lado, estimulante e, por outro, angustiante.

É que existem obras, em analogia às que Bloom (2002) aponta, nas quais a influência do Professor Monteiro - isto é, da "semeadura" do ritmo climático - é negada e o paradigma não é utilizado; noutras, a influência é bem aceita, o autor diz que trabalhará na perspectiva rítmica mas, de fato, não emprega o paradigma; noutras obras ainda, a influência também é bem aceita , o autor diz que fará a análise rítmica e, assim sendo, chega mesmo a construir os gráficos com as variações diárias e horárias dos elementos climáticos, porém, como não faz a interpretação da circulação atmosférica não emprega o paradigma.

Além dessas, existem as obras que apresentam os procedimentos mencionados e, também, a correta identificação dos sistemas atmosféricos atuantes. Só que seus autores, ao invés de buscarem a explicação dos fatos nas cadeias rítmicas (tipos de tempo fundamentais), procuram-na nos índices de participação das massas de ar e frentes e alcançam a gênese do fenômeno (pluvial, térmico etc.). Alguns, além de tudo isso, à partir da tipologia das invasões polares (Monteiro, 1969; Tarifa, 1975), realizam sínteses que podem vir sob a forma de texto ou de esboços cartográficos. Enfim, para não me alongar, outras maneiras de interpretar a "bula" ainda poderiam ser identificadas, o que representa, sem dúvida, a angústia da influência.

Dessa maneira, à luz da obra de Bloom (2002), talvez uma nova crítica pudesse vir a ser feita. Eu, sinceramente, não acredito ter condições para tanto. Faltar-me-iam muitos elementos para alcançar o que ele propõe. Ademais, quanto é que a Climatologia Geográfica tem de poesia para que se possa fazer a justa analogia? Seria necessário, para tanto, atribuir ao Professor Monteiro o papel de "Shakespeare"6 e a Pédelaborde o de "Shakespeare francês" ${ }^{\prime 7}$. Esse tipo de comparação não sei se agradaria ao Mestre. Possivelmente não. Ele que já não aceita a óbvia insígnia de criador de uma escola, como é que iria aceitar a de ser o autor das mais puras verdades de que

6 Bloom (2002, p.14) explica que excluiu Shakespeare "de A ansiedade da influência e sua seqüência imediata porque não estava preparado para meditar sobre Shakespeare e originalidade. Não se pode resolver a questão da influência sem levar em conta o mais influente de todos os autores nos últimos quatro séculos. Às vezes desconfio de que na verdade não nos ouvimos uns aos outros porque os amigos e amantes de Shakespeare jamais ouvem o que os outros estão dizendo, o que faz parte da irônica verdade de que Shakespeare em grande parte nos inventou. A invenção do humano, como o conhecemos, é um modo de influência que ultrapassa de longe qualquer coisa literária."

7 Para Bloom (2002, p.15) "Neomarxistas, neofeministas, neo-historicistas, teóricos influenciados pelos franceses, todos demonstram seu materialismo cultural dando-nos um Shakespeare menor, puro produto das "energias sociais" do Renascimento inglês. Minha piada favorita a esse respeito é acrescentar a Lacan, o "Freud francês", e Derrida, o "Joyce francês", o triunfo último da chamada "teoria": Foucault, o "Shakespeare francês". Os franceses jamais valorizaram a originalidade, e até a chegada de um tardio romantismo à França, jamais gostaram muito das peças de Shakespeare. Ainda o apreciam um tanto menos que os indonésios, os japoneses ou os americanos. Os verdadeiros multiculturalistas, em todo o globo, aceitam-no como um autor indispensável, diferente de todos os outros em grau, e por uma tão larga margem que chega a ser de uma espécie diferente. Shakespeare, como afirmei à exaustão em outra parte, muito simplesmente não é apenas o cânone ocidental; é também o cânone mundial. O fato de seu apelo ser igual para as platéias de todos os continentes, raças e línguas (sempre excluindo os franceses), parece-me uma absoluta refutação de nossas atuais opiniões da moda, predominantes sobretudo na Grã-Bretanha e nos Estados Unidos, que insistem num Shakespeare culturalmente preso pela história e a sociedade." 
a Climatologia Geográfica necessita? Em outras palavras, ele não admite ternos "inventado", a nós, seus discípulos diretos ou indiretos, não importa. Muitos desavisados poderiam interpretar essa analogia e as conseqüentes comparações como um tipo de deboche. E, quero já esclarecer, tal ousadia nem me passa pela cabeça.

Bem, mas finalizando essa linha de raciocínio, desde que a analogia fosse feita, as obras dos discípulos do Mestre seriam então "classificadas" numa ou mais das Seis Proporções Revisionárias da Sinopse de Bloom (2002, p.6465):

1. Clinamen, leitura distorcida ou apropriação mesmo; tomo a palavra de Lucrécio, onde ela significa um "desvio" dos átomos para possibilitar a mudança no universo. O poeta desvia-se de seu precursor, lendo o poema dele de modo a executar o clinamen em relação a ele. Isso aparece como um movimento corretivo em seu próprio poema, que sugere que o poema do precursor seguiu certo até um determinado ponto, mas depois deve terse desviado, precisamente na direção em que segue o novo poema.

2. Tessera, completude e antítese; tomo a palavra não da fabricação de mosaicos, onde ainda é usada, mas dos cultos de mistério antigos, onde queria dizer um sinal de reconhecimento, o fragmento, digamos, de uma pequena jarra, que com os outros fragmentos reconstituiria o vaso. O poeta "completa" antiteticamente seu precursor, lendo o poema-pai de modo a reter seus termos, mas usando-os em outro sentido, como se o precursor não houvesse ido longe o bastante.

3. Kenosis, dispositivo de decomposição semelhante aos mecanismos de defesa que nossa mente emprega contra as compulsões de repetição; é portanto um movimento de descontinuidade em relação ao precursor. Tomo a palavra de São Paulo, onde quer dizer a submissão ou esvaziamento de Jesus por si mesmo, quando aceita a redução de status, de divino para humano. O poeta que vem depois, aparentemente esvaziando-se de seu próprio estro, sua divindade imaginativa, parece submeter-se, como se estivesse deixando de ser poeta, mas esse refluxo é realizado em relação ao poema de refluxo do precursor de um modo que também se esvazia o precursor, e assim o poema de esvaziamento posterior não é tão absoluto quanto parece.

4. Daemonização, movimento para um Contra-Sublime personalizado, em relação ao Sublime do precursor; tomo o termo do uso neoplatônico generalizado, onde um ser intermediário, nem divino nem humano, entra no adepto para ajudá-lo. O poeta que vem depois abre-se para o que acredita ser um poder no poema-pai que não pertence ao pai mesmo, mas a uma gama de ser logo além desse precursor. Ele faz isso, em seu poema, colocando a relação da obra com o poema-pai de modo a desfazer pela generalização a unicidade da obra anterior.

5. Askesis, movimento de autopurgação, que se destina a atingir um estado de solidão; tomo o termo, por mais geral que seja, sobretudo da prática de xamãs pré-socráticos como Empédocles. O poeta que vem depois não passa, como na kenosis, por um movimento revisionário de esvaziamento, mas de redução; abre mão de parte de seu dom humano e imaginativo para separar-se de outros, incluindo o precursor, e faz isso em seu poema colocando-o em relação ao poema-pai de modo a fazer com que esse poema também passe por uma askesis; o talento do precursor é igualmente truncado.

6. Apophrades, ou retorno dos mortos; tomo a palavra dos tristes e infelizes tempos atenienses em que os mortos voltavam a habitar as casas onde 
haviam morado. O poeta que vem depois, em sua própria fase final, já assoberbado por uma solidão imaginativa que é quase um solipsismo, mantém seu poema de novo tão aberto à obra do precursor que a princípio podemos acreditar que a roda completou um círculo completo, e que estamos de volta ao inundado aprendizado do poeta posterior, antes que sua força começasse a afirmar-se nas proporções revisionárias. Mas o poema é agora mantido aberto ao precursor, quando antes estava aberto, e o efeito fantástico é que a realização do novo poema o faz parecer a nós não como se fosse o precursor a estar escrevendo-o, mas como se o próprio poeta posterior houvesse escrito a obra característica do precursor.

Como se pode ver essa nova forma de interpretar e criticar as obras posteriores ao poema-pai - quer dizer, à Obra do Mestre - demandaria tempo e outras (re)visões, não simplesmente aquelas já concretizadas (Zavattini, 2001; 2004). Porém, não resta dúvida que se esse novo tipo de análise das obras dos discípulos - diretos e indiretos - viesse a ser efetivado, mais luzes seriam lançadas sobre a nossa produção e a influência do Professor Monteiro. Fica a idéia.

E ao concluir esse longo raciocínio gostaria de me explicar. Afinal, muitos devem estar se perguntando: Como é que a obra de Bloom (2002), que trata de crítica da poesia, veio parar no VI Simpósio Brasileiro de Climatologia Geográfica e, mais especificamente, nessa mesa redonda que trata da interação com outros campos do conhecimento? A primeira explicação remonta a uma passagem bastante prosaica. Após ter finalizado a tese de livre-docência em novembro de 2001, enquanto aguardava o concurso público para professor adjunto, enviei uma cópia ao Mestre, para que a criticasse. Quando, em fevereiro de 2002, ele a discutiu comigo, mencionou en passant a obra de Bloom. Na ocasião, preocupado com o concurso que se aproximava, não dei a devida importância àquela menção. A segunda explicação, também trivial, refere-se à recente fase de transformação daquela tese em livro. Tendo o editor me sugerido pedir o prefácio ao Professor Monteiro, eis que nele (re)aparecem Bloom, a angústia da influência e a teoria da poesia. Assim que o li, e já convidado para participar deste evento pela prezada Profa Dra Josefa Eliane Santana de Siqueira Pinto, ocorreu-me proceder do presente modo, numa derradeira tentativa de não cair na mesmice, embora tenha a nítida sensação de estar, lamentavelmente, me repetindo. E isso deve ser a angústia da influência!

\section{CLIMATOLOGIA GEOGRÁFICA: teoria, interações, dados e perspectivas.}

Uma área do saber como a da Climatologia Geográfica, cujo referencial teórico é simples e de fácil compreensão, pode e deve interagir com outros campos da ciência. Afinal, nós geógrafos, tomamos o conceito de Sorre (1951) como a nossa "teoria do clima" (série dos estados da atmosfera sobre um lugar em sua sucessão habitual); amparamo-nos (amparar - pai - poemapai) na análise rítmica (Monteiro, 1971) para representar as cadeias fundamentais dos tipos de tempo; usamos cartas isobáricas e imagens de satélite para compreender, em diferentes espaços climáticos, a repercussão de vários fenômenos meteorológicos (Monteiro, 1976; 1999); utilizamos os "anospadrão" como amostragem sui generis que, dentre outras vantagens, nos 
permite escapar da "ditadura" das "normais climatológicas", contornar as freqüentes falhas em séries temporais, e encontrar - nas respostas do "lugar" à circulação atmosférica regional - as unidades, sub-unidades e feições climáticas (Monteiro, 1973), além de muitos outros procedimentos que costumamos adotar.

Todavia, essas "novidades" precisariam ser devidamente explicadas, ensinadas aos outros ramos do saber. Creio, mesmo, que se essa "teoria" da climatologia geográfica for bem aplicada nas áreas do conhecimento médico, agrícola, urbano, industrial, de transportes, e em inúmeras outras, muitos poderão ser os beneficiados. Afinal, não dá mais para fazer "vista grossa" ao uso abusivo, nos diversos campos da ciência, de dados médios (ou "normais"), de estatísticas inadequadas, enfim, de práticas que isolam os componentes do "complexo" atmosférico, pois como ensina Pédelaborde (1970, p.23-24):

Ce qui importe, c'est la façon dont le complexe se manifeste, le tableau qu'il réalise et l'action physiologique qu'il exerce. Ce qui importe aussi, ce sont les conditions qui déterminent ce complexe: d'où provient la masse d'air, combien de temps a-t-elle séjourné sur le Bassin arctique, sur le $N$ de I'Atlantique, dans les parages des Açores ou sur les steppes russes, quelle trajectoire suit-elle, de quels mécanismes physiques est-elle le siège, quelles dénaturations a-t-elle subies avant d'atteindre le point d'observation. Enfin la durée sera envisagée, ainsi que les phénomènes qui déterminent cette durée et qui mettent fin au type. Une tele étude, à condition qu'elle embrasse la totalité des types, qu'elle calcule leur fréquence et la façon dont ils se succèdent au cours d'une longue période, restituera l'ambiance vraie dont parle SORRE. Elle aura saisi la réalité des temps e la complexité vivante du climat. Elle seule fournira une conception génétique qui s'ajoutera aux données précieuses mais incomplètes de l'étude séparative. Elle possèdera donc déjà une valeur indiscutable au point de vue de la géographie physique pure. D'autre part, elle seule pourra nous mettre sur la voie de la synthèse totale qui est le rêve de tout géographe, parce que les réactions du milieu vivant n'ont pas grand'chose à voir avec les moyennes, mais dépendent des conditions vraies du temps, de leur durée et de leur succession.

Mas, basta deixar de lado a enfática "totalidade" dos tipos de tempo ("sonho-síntese" de Pédelaborde) e usar apenas o paradigma do ritmo para se obter uma boa "colheita" em qualquer ramo do campo científico. Ao tratar de interações, Pédelaborde (1970) mostra a necessidade de se estabelecer um ponto indispensável entre o domínio da Climatologia Geográfica e o da Meteorologia Dinâmica. Esse autor, entretanto, na tese de doutorado, ao estudar a "totalidade" dos tipos de tempo sobre a bacia parisiense apenas alcançaria inúmeros "catálogos" atmosféricos (Pédelaborde, 1957). No Brasil, em tese de idêntico grau, ao analisar do ponto de vista rítmico dois distintos "invernos-padrão", o Mestre vislumbraria a "tipologia" dos fluxos de invasão polar na América do Sul e explicaria, com eficácia, a sucessão habitual e excepcional dos tipos de tempo sobre vasta porção de nosso território.

Cabe, aqui, a seguinte pergunta: Quem, afinal, chegou mais perto da "síntese total"? Quem conseguiu, verdadeiramente, estabelecer o ponto intermediário entre a Meteorologia e a Geografia? A resposta já sabemos, pois antes do Professor Monteiro, alguns geógrafos brasileiros já tentavam utilizar os recursos da Meteorologia Dinâmica. Mas, quando muito, usavam-nos para ilustrar alguns tipos de tempo em seus estudos de caso. Já o Professor Monteiro utilizou-os de maneira equilibrada, ou seja, não exagerou tentando alcançar a "totalidade" dos tipos de tempo nem serviu-se deles apenas para revelar certos 
"momentos" atmosféricos. Assim, a Obra do Mestre atingiu um nível de explicação nunca antes alcançado. Esta é uma de suas inúmeras contribuições!

Pédelaborde (1970), que na metade do século passado já discutia o sério problema da falta de dados, explorava a questão mostrando a péssima distribuição da rede meteorológica no hemisfério sul e nas áreas glaciais, desérticas ou desabitadas. Esse problema, que até hoje persiste, ainda apresenta outras facetas em nosso país, onde à obsoleta, mal distribuída e pouco densa rede de observações meteorológicas soma-se, também, o difícil acesso a seus dados. No Brasil, a tarefa de levantar dados "oficiais" para trabalhar "geograficamente" o clima pode provocar grande frustração, embora não devesse. Afinal, os elementos do clima tanto podem ser analisados pela Geografia como pela Meteorologia, Agronomia, Medicina, Arquitetura, Engenharia, Biologia etc. Esses ramos científicos, cada um com suas próprias perspectivas e méritos que Ihe são inerentes, deveriam caminhar lado a lado e ajudarem-se mutuamente. Mas, lamentavelmente, a realidade é outra. Falo por experiência própria e, também, em nome de muitos outros, pois embora não tenha tido dificuldades na coleta de dados durante o mestrado e o doutorado, as teria um pouco mais tarde. Assim, vejo com pesar o sofrimento de muitos, especialmente dos meus orientandos que, iludidos, fazem projetos envolvendo enorme volume de dados meteorológicos e acham que irão obtê-los prontamente. Entretanto, quando enfrentam a dura realidade dos fatos, tornam-se pessimistas e, assim, belos projetos de pesquisa em climatologia geográfica são inviabilizados ou, no mínimo, tornam-se bastante acanhados. Não é fácil tratar dessas questões, pois elas causam enorme constrangimento quando se recorre aos órgãos "oficiais" detentores da informação meteorológica no Brasil. No entanto, o local e o momento, creio, são os mais apropriados.

\section{EPÍLOGO: reflexões sobre a teoria do clima como Via.}

Ao encerrar esta prolixa explanação gostaria de agradecer a atenção e paciência que me foram dispensadas, e de alertar para o fato de que o clima pode não passar de uma teoria ${ }^{8}$. Desta forma, ao passo em que o horizonte se amplia, nessa amplidão tudo pode se confundir. Basta lembrar que já fomos alertados sobre o nosso parco vocabulário técnico, pois segundo Sorre (1951), quando queremos definir um clima do ponto de vista médico, temos a mesma riqueza e a mesma precisão de Hipócrates. Mas, Sorre nos redime, ao dizer que ganhamos porque vemos melhor o sentido das pesquisas necessárias, o que, para ele, já seria um grande progresso. E para nós, o que é o progresso? Quando me conscientizo que a figura usada por Aristóteles para representar a formação dos meteoros (Staszak, 1992, p.108) praticamente "reaparece" nos manuais de climatologia de hoje, não vejo o progresso. Quando contabilizo o recente levantamento da produção em climatologia geográfica no período de 1971 a 2000 e o agrupo por assunto, acredito no progresso. Porém, quando me recordo que esse mesmo levantamento mostra que o paradigma que ampara

8 S'interroger sur le climat, ce n'est pas choisir dans le Monde un objet qui s'impose pour le soumettre à une analyse en quelque sorte obligée. Le climat n'existe pas, ou plus exactement il n'a d'autre réalité que dans le langage: il relève d'une catégorisation qui renvoit au moins autant à une pratique discursive et une idéologie qu'au monde phénoménal. On ne doit pas penser le climat, on peut le penser; mais on peut aussi bien ne pas le penser, ou penser autre chose. Le concept, puisque c'est de cela qu'il s'agit, date d'ailleurs du XIXème siècle. Si, étymologiquement, le mot est grec, le concept ne l'est pas (Staszak, 1992, p.105-106). 
(pai - poema-pai) a nossa "teoria" do clima não foi plenamente utilizado, compreendo que muito ainda temos que refletir e caminhar, na teoria e na prática da Climatologia Geográfica. E, ao mesmo tempo, também compreendo que já chegamos ao lugar, ou sempre estivemos nele?

\section{Reflexões sobre a Via}

Cavalgando três dias e três noites ele chegou ao lugar, mas decidiu que ao lugar não se podia chegar.

Parou, pois, para pensar.

Este deve ser o lugar. Se cheguei a ele, então não tenho importância.

Ou pode não ser este o lugar. Não há, pois, importância, mas eu próprio não sou diminuído.

Ou pode ser este o lugar. Mas talvez eu não tenha chegado a ele. Posso ter estado sempre aqui.

Ou ninguém está aqui, e eu simplesmente sou do lugar e nele estou. E ninguém pode chegar a ele.

Talvez este não seja o lugar. Eu tenho, pois, um propósito, sou importante, mas não cheguei a ele.

Mas este deve ser o lugar. E como não posso chegar a ele, eu não sou, não estou aqui, aqui não é aqui.

Após cavalgar três dias e três noites ele não chegou ao lugar, e tornou a afastar-se cavalgando.

Dar-se-ia que o lugar não o conhecesse, ou não o encontrasse? Não era ele capaz?

Na história só se diz que se deve chegar ao lugar.

Cavalgando três dias e três noites ele chegou ao lugar, mas decidiu que ao lugar não se podia chegar. (Bloom, 2002, p.207).

\section{Está aberto o debate!}

\section{ReferênciasBibliográficas}

BLOOM, H. A Angústia da Influência: uma teoria da poesia. Rio de Janeiro: Imago, 2002.

MONTEIRO, C.A.F. A Frente Polar Atlântica e as Chuvas de Inverno na Fachada Sul-

Oriental do Brasil (Contribuição metodológica à análise rítmica dos tipos de tempo no

Brasil). São Paulo: IGEOG/USP, 1969.

Análise Rítmica em Climatologia: problemas da atualidade climática em São

Paulo e achegas para um programa de trabalho. São Paulo: IGEOG/USP, 1971.

. A Dinâmica Climática e as Chuvas no Estado de São Paulo - estudo geográfico sob forma de atlas. São Paulo: IGEOG/USP, 1973.

. Teoria e Clima Urbano. São Paulo: IGEOG/USP, 1976.

. Clima e Excepcionalismo (Conjecturas sobre o Desempenho da Atmosfera

como Fenômeno Geográfico). Florianópolis: UFSC, 1991.

. Prefácio. In: SANT'ANNA NETO, J.L; ZAVATINI, J.A. (Orgs.). Variabilidade e

Mudanças Climáticas: implicações ambientais e socioeconômicas. Maringá: Eduem, 2000. p.9-13.

PÉDELABORDE, P. Le Climat du Bassin Parisien: essai d'une méthode rationelle de

climatologie physique. Paris: Medicis, 1957.

Introduction a l'Étude Scientifique du Climat. Paris: Sedes, 1970. 
SORRE, M.. Les Fondements de la Géographie Humaine. Paris: Armand Colin, 1951.

STASZAK, J-F. A la recherche du climat dans Les Meteorologiques et dans I'oeuvre d'Aristote. In: Géographie et Cultures (1: 105-118). Paris: L'Harmattan, 1992.

TARIFA, J.R. Fluxos Polares e as Chuvas de Primavera-Verão no Estado de São Paulo (Uma análise quantitativa do processo genético). São Paulo: IGEOG/USP, 1975.

AVATINI, J.A.. Variações do Ritmo Pluvial no Oeste de São Paulo e Norte do Paraná (eixo Araçatuba - Presidente Prudente - Londrina). São Paulo: USP/FFLCH, 1983. Dissertação (Mestrado).

. A Dinâmica Atmosférica e a Distribuição das Chuvas no Mato Grosso do Sul. São Paulo: USP/FFLCH, 1990. Tese (Doutorado).

ZAVATTINI, J.A. O Paradigma do Ritmo na Climatologia Geográfica Brasileira (Teses e dissertações dos programas paulistas de pós-graduação - 1971-2000). Rio Claro: UNESP/IGCE, 2001. Tese (Livre-docência em Climatologia).

. Estudos do Clima no Brasil. Campinas: Alínea, 2004. 